E3S Web of Conferences 1, 30004 (2013)

DOI: $10.1051 / \mathrm{e} 3$ sconf/20130130004

(C) Owned by the authors, published by EDP Sciences, 2013

\title{
Lead and Cadmium: Priorities for action from UNEP's perspective for addressing risks posed by these two heavy metals
}

\author{
D. Piper $^{1}$ and J. F. Caicedo Restrepo ${ }^{2}$ \\ ${ }^{1}$ Deputy, United Nations Environment Programme, Division of Technology, Industry and Economics, Chemicals Branch, \\ Geneva, Switzerland, david.piper@unep.org \\ ${ }^{2}$ Programme Officer, United Nations Environment Programme, Division of Technology, Industry and Economics, \\ Chemicals Branch, Geneva, Switzerland, juan.caicedo@ unep.org
}

\begin{abstract}
The United Nations Environment Programme (UNEP) has been focusing on actions with regard to lead and cadmium since 2001 when the work of the Partnership for Clean Fuels and Vehicles (PCFV) was initiated. The development and finalization of the reviews of scientific information on lead and cadmium facilitated discussions among Governments in relation to the need for global action with regard to these heavy metals. UNEP continues to address priority areas for focusing to reduce risks posed by lead and cadmium. The Global Alliance to Eliminate Lead Paint (GAELP) is a clear example for addressing those risks; however more work is expected to be done in relation to these key issues.
\end{abstract}

Keywords: lead, cadmium, United Nations Environment Programme, UNEP, Governing Council, PCFV, GAELP

\section{Introduction}

The Governing Council (GC) of the United Nations Environment Programme (UNEP), in connection with its discussions relating to the need for global action to deal with the adverse impacts of mercury pollution, has discussed the possible need for global action with regard to other heavy metals, such as lead and cadmium, on several occasions.

The focus of discussions in 2001 and 2003 was to accelerate the process of eliminating the use of lead in gasoline, in which UNEP has played a key role through its work with Governments and others stakeholders within the framework of the Partnership for Clean Fuels and Vehicles (PCFV).

In 2003, the UNEP GC decision also urged commitment to phase out lead-based paint and lead in other sources of human exposure to prevent exposure to lead.

In 2005, the UNEP GC decision 23/9 III, requested UNEP to undertake the development of reviews of scientific information on lead and cadmium, focusing especially on long-range environmental transport, in order to inform future discussions of the GC of UNEP on the need for global action in relation to lead and cadmium.

By its decision 24/3 III of 9 February 2007 on lead and cadmium, the GC of UNEP acknowledges the data and information gaps identified in the UNEP reviews on lead and cadmium and that further action is needed to fill those data and information gaps, taking into account the specific situation of developing countries and countries with economies in transition.

In 2009, the UNEP GC decision 25/5 II, requested UNEP to finalize the scientific review taking into account the latest available information.

Last year, the UNEP GC set out a way forward in a number of important areas that include lead and cadmium. Throughout decision 26/3 I, it was noted that there remains a need for a continued focus to reducing the risks posed by lead and cadmium.

The Global Alliance to Eliminate Lead Paint (GAELP) is a clear example of the UNEP's priorities for action for addressing risks posed by lead and cadmium. 
More work is expected to be done in relations to other new and used products containing lead and cadmium as it remains a challenge for developing countries and countries with economies in transition which lack the capacity to manage and dispose of the substances in products in an environmentally sound manner.

\section{Materials and Methods}

UNEP has used a similar process to that followed in developing the 2002 UNEP Global Mercury Assessment report when undertaking the review of scientific information on lead and cadmium.

The reviews of scientific information on lead and cadmium were developed thanks to the establishment of a working group from Governments, intergovernmental and non-governmental organisations.

Working Group members assisted, first through a comment round by mail, then through the First Meeting of the Lead and Cadmium Working Group, which took place 18-22 September 2006 in Geneva, Switzerland, to the development and finalization of these reviews of scientific information. Additional sources of information for the review included publications, articles and reports of relevance to lead identified through a literature search in scientific literature as well as information, publications and reports publicly available.

\section{Results and Discussions}

Lead is mined in more than 40 countries, the major producers being China and Australia, which represent about 30 per cent and 22 per cent of global mining production respectively.

The total global production of lead from mining has decreased slightly, from 3.6 million tonnes in 1975 to 3.1 million tonnes in 2004. Over the same period, global refined lead production and metal consumption have increased from about 4.7 million tonnes to about 7.1 million tonnes. The reason for the difference between mine production and lead consumption is due to the fact that recycled lead accounts for an increasingly large part of the supply: recycled lead accounted for 45 per cent of global supply in 2003.

Lead is used and traded globally as a metal in various products. The major use of lead in recent years is lead batteries, accounting for 78 per cent of reported global consumption in 2003. Other major application areas are lead compounds ( 8 per cent of the total), lead sheets ( 5 per cent), ammunition ( 2 per cent), alloys ( 2 per cent), cable sheathing (1.2 per cent), and petrol additives (less than 1 per cent). The most significant change in the overall use pattern over the period 1970 - 2003 is that batteries account for an increasing part of the total, whereas the share of cable sheathing and petrol additives has decreased. Lead as pigment in paints has been discontinued in developed countries but is still used in some developing countries, specifically in industrial settings.

Cadmium is produced mainly as a by-product of mining, smelting and refining of zinc and, to a lesser degree, as a by-product of lead and copper production. It is therefore primarily a function of zinc production rather than cadmium demand. Global cadmium production almost doubled between 1950 and 1990. Since 1990, global consumption has remained constant, at about 20,000 tonnes per year, although major changes have occurred with the geographical distribution of this production. Until 1997, production in Europe, the Americas and Asia remained constant. Since 1997, however, production in Asia has increased sharply, whereas the production in Europe has decreased. Major shifts in smelting and refining technology by many of the world's zinc refiners from pyrometallurgical to hydrometallurgical processes (50 per cent in 1958 to 81 per cent of capacity in 2003) have led to significant decreases in releases of cadmium to the environment.

Recycled cadmium accounts for about 18 per cent of total global supply. Countries with significant collection and recycling activities include France, Germany, Japan, the Republic of Korea, Sweden and the United States of America.

Cadmium is used and traded globally as a metal and as a component in various products. A growing proportion of refined cadmium consumption is accounted for by $\mathrm{NiCd}$ batteries, which in 2004 represented 81 per cent of the total. Other major uses of refined cadmium are: pigments for plastics, ceramics and enamels; stabilizers for plastics; plating on iron and steel; and as an alloying element of some lead, copper and tin alloys. Since 1990, consumption for pigments, stabilizers, alloys and other uses has decreased significantly.

Products containing lead and cadmium are not typically collected separately from the general waste streams in developing countries. Therefore lead and cadmium discharges will end up in municipal waste and disposed of in landfills, incineration, open burning or indiscriminate dumping. Some of the lead and cadmium in these products will be released to the environment, the extent of which depends on disposal method, control technologies applied and other factors.

As awareness of the adverse impacts of lead and cadmium has increased, many uses have been reduced significantly in industrialized countries. In addition, as public awareness has grown, waste management systems have increasingly been put in place in industrialized countries to reduce releases of lead and cadmium to the environment. That said, however, some of the uses of lead and cadmium which have been phased out in industrialized 
countries have continued in developing countries. In addition, the use of lead and cadmium has continued or increased in some less developed regions or countries, for example, in plastics or in paints. Regulations and restrictions are less comprehensive or less well enforced in some developing regions.

This has resulted in some of the health and environmental risks, local and regional that accompany the use, management (including collection, storage, recycling and treatment) and disposal of products containing lead. These hazardous disposal practices include open burning and indiscriminate dumping in sensitive ecosystems such as rivers and wetlands.

Another issue faced by developing countries is the export of new and used products containing lead and cadmium, including electronic equipment and batteries, to those countries which lack the capacity to manage and dispose of the lead and cadmium in these products in an environmentally sound manner at the end of their life. An additional problem is posed by products containing lead and cadmium that may cause exposure through normal use, such as certain toys.

Environmental transport pathways explored in the reviews include atmospheric transport, ocean transport, river transport and transport in large, transboundary lakes.

Long-range transport in the environment here refers to transport in air or water of substances (e.g. lead and cadmium) whose physical origin is situated in one country and which are transported and deposited to another country at such a distance that it may not generally be possible to distinguish the contribution of individual emission sources. Regional transport here refers to such transport within a geographical region such as for example Africa or North America, whereas intercontinental transport refer to such transport from one continent to another, for example between Asia and North America.

Atmospheric transport is currently considered the most important mechanism of long-range lead and cadmium dispersion in the environment. Once emitted to the atmosphere, lead and cadmium may be transported locally, regionally, or intercontinentally depending on various factors, including particle size, the height of the emissions outlet and meteorology. Because they have a relatively short residence time in the atmosphere (days or weeks), these metal is mainly transported over local, national or regional distances. Under certain conditions, lead and cadmium can be transported by airflows over hundreds or even thousands of kilometres, and can contribute to the exposures to lead and cadmium for humans and ecosystems at locations far away from the emission source.

Emitted lead and cadmium are primarily transported atmospherically over local, national or regional distances; that is, within the region or continent where the lead and cadmium were originally emitted. Intercontinental atmospheric transport.

Extensive data regarding lead and cadmium concentrations in the water column exist for specific locations in the world's oceans, and for different years over the last two to three decades. Some examples suggest that ocean transport may be an important pathway. In addition, the nature of ocean currents indicates their potential for the transport of pollutants on a global scale. Global, deep-sea ocean currents are (with varying strength) connected to one big, dynamic system, the so-called thermohaline circulation or "global conveyer belt", which transports enormous water masses through the Atlantic Ocean, the Southern Ocean around Antarctica, and the Pacific Ocean. The existence of ocean transport modelling of other pollutants (such as persistent organic pollutants, or POPs) demonstrates that ocean modelling for heavy metals may be relevant.

Due to lack of hemispherical or global emission datasets, intercontinental cadmium transport has not been assessed in transport models so far. However, cadmium transport in the atmosphere is governed by the same transport principles as other particle-bound heavy metals, such as lead. Indeed, atmospheric transport characteristics of cadmium and lead are completely defined by properties of their carrier particles.

\section{Conclusions}

The reviews of scientific review on lead and cadmium took into account the latest available scientific information in relation to these two metals. They allowed that the UNEP GC set out a way forward in a number of important areas related to lead and cadmium. It was noted that there remains a need for a continued focus to reducing the risks posed by lead and cadmium. The approach that UNEP has followed to target those actions is a voluntary stakeholder involvement throughout the work in partnerships.

The Global Alliance to Eliminate Lead Paint (GAELP) is a clear example of the UNEP's priorities for action for addressing risks posed by lead and cadmium. The Global Alliance is a voluntary collaborative initiative to focus and catalyze the efforts of a diverse range of stakeholders to achieve international goals to prevent children's exposure to lead from paint and to minimize occupational exposures to lead paint. The Global Alliance is a joint undertaking of the United Nations Environment Programme (UNEP) and the World Health Organization (WHO).

More work is expected to be done in relations to other new and used products containing lead and cadmium as it remains a challenge for developing countries and countries with economies in transition which lack the capacity to manage and dispose of the substances in products in an environmentally sound manner. 
E3S Web of Conferences

\section{References}

UNEP, reviews of scientific information on lead and cadmium, 2010. http://www.unep .org/ hazardoussubstances/ (Lead and Cadmium Sections) 